\title{
(2) OPEN ACCESS \\ Do socioeconomic and birth order gradients in child maltreatment differ by immigrant status?
}

\author{
Kathleen S Kenny (D), ${ }^{1}$ Ariel Pulver, ${ }^{2}$ Patricia O'Campo, ${ }^{2,3}$ Astrid Guttmann, ${ }^{4,5,6,7}$ \\ Marcelo L Urquia $1,2,6$
}

- Supplemental material is published online only. To view please visit the journal online (http://dx.doi.org/10.1136/ jech-2019-212759).

For numbered affiliations see end of article.

Correspondence to Kathleen S Kenny, Community Health Sciences, Max Rady College of Medicine, University of Manitoba Manitoba Centre for Health Policy, Winnipeg R3E 3P5, Canada;

kathleen_kenny@cpe. umanitoba.ca

Received 4 June 2019 Revised 29 June 2020 Published Online First 16 September 2020

\section{Check for updates}

(c) Author(s) (or their employer(s)) 2021. Re-use permitted under CC BY-NC. No commercial re-use. See rights and permissions. Published by BMJ.

To cite: Kenny KS, Pulver A, O'Campo P, et al. J

Epidemiol Community Health 2021;75:22-28.

\begin{abstract}
Background While literature has documented strong gradients in child maltreatment (CM) by socioeconomic status and family composition in the general population, how these patterns extend to immigrants remain inconclusive. Using population-based administrative data, we examined, for the first time, whether gradients in CM by neighbourhood income and childbirth order vary by immigrant status.

Methods We used linked hospitalisation, emergency department visits, small-area income, birth and death records with an official Canadian immigration database to create a retrospective cohort of all 1240874 children born from 2002 to 2012 in Ontario, Canada, followed from 0 to 5 years. We estimated rate ratios of $\mathrm{CM}$ among immigrants and non-immigrants using modified Poisson regression.

Results CM rates were 1.6 per 100 children among nonimmigrants and 1.0 among immigrants. CM was positively associated with neighbourhood deprivation. The adjusted rate ratio $(A R R)$ of $C M$ in the lowest neighbourhood income quintile versus the highest quintile was 1.57 (95\% $\mathrm{Cl} 1.49$ to 1.66$)$ for non-immigrants and $1.33(95 \% \mathrm{Cl}$ 1.15 to 1.54$)$ for immigrants. The socioeconomic gradient disappeared when restricted to children of immigrant mothers arrived at 25+ years and in analyses excluding emergency department visits. Compared to a first child, the ARR of CM for a fourth or higher-order child was 1.75 (95\% Cl 1.63 to 1.89 ) among non-immigrants and 0.57 (95\% Cl 0.44 to 0.74 ) among immigrants.

Conclusions Immigrants exhibited lower CM rates than non-immigrants across neighbourhood income quintiles and differences were greatest in more deprived neighbourhoods. The contrasting birth order gradients between immigrants and non-immigrants require further investigation.
\end{abstract}

\section{INTRODUCTION}

Child maltreatment (CM) is a major and persisting public health concern that can lead to child protective services (CPS) investigations and have effects on health throughout the life course. ${ }^{1}$ Despite increasing research on the relationship between social and economic factors and $\mathrm{CM}^{23}$ and strong evidence of the roles of poverty and race/ethnicity in shaping contact with CPS, ${ }^{4-6}$ knowledge of how these dynamics extend to immigrant families is inconclusive. ${ }^{7}$

Migration encompasses a broad range of conditions that may differentially influence CM risk. Previous literature on immigrants identifies several stressors including lack of material resources, disrupted social support systems, premigration trauma and postmigration/resettlement stress that may lead to less supportive parenting practices and increased risk of CM. ${ }^{8}$ At the same time, for many immigrants, reasons for migrating and a desire of a better life for children, as well as the preponderance of two-parent families and lower use of drugs and alcohol, ${ }^{10}{ }^{11}$ have been posited as protective in reducing risk. ${ }^{7} 10$

By virtue of immigrants more often living on low incomes and residing in larger households, the roles of socioeconomic conditions ${ }^{12}$ and, less so, family composition have been set forth as two hypothetical mechanisms that underlie CM risk in this population. These mechanisms may restrict parents' abilities to meet children's basic needs ${ }^{2} 13$ or increase parenting stress and depression, which in turn may result in harsher parenting or neglect. ${ }^{14-16}$ Among immigrants, literature on links between socioeconomic conditions and CM is mixed, with two studies from the USA and Europe reporting that differences in CM between immigrants and non-immigrants completely disappear after adjustment for an individual-level socioeconomic indicator (ie, income, education or employment) ${ }^{7} 17$ and other studies (all from Europe) ${ }^{8} 1819$ showing a partial decline. The relationship between birth order and CM among immigrants is also unclear, and though larger family size is associated with increased CM risk in the general population, ${ }^{13} 20$ the pattern among immigrants, who generally have larger families, has not been investigated.

To advance understanding of contexts of CM risk among immigrants, the present study investigated patterns in hospital-based records of CM among immigrant and non-immigrant children. We used linked longitudinal population-based administrative data on all children aged $0-5$ years born in the province of Ontario, Canada. Canada has the second highest proportion of immigrants in the world (21\%), following Australia (27\%), and among Canadian jurisdictions, the province of Ontario has the largest share of immigrants. ${ }^{21}$ Administrative health data have been recently adopted for epidemiological research on $\mathrm{CM}^{22}$ and have been used for the purpose of population-level comparisons in CM rates. ${ }^{1}$ We examined associations between neighbourhood income and childbirth order with health system-identified maltreatment in children aged $0-5$ years by maternal immigrant status. We used gradients as a conceptual approach to identify whether and to what extent disparities exist based on immigrant status and to inform potential leverage points for prevention.

\section{METHODS}

\section{Sample}

This population-based cohort study was conducted in Ontario, Canada, where universal healthcare is 
provided to children and adult residents under the Ontario Health Insurance Plan, covering costs for all citizens, refugees, permanent residents or persons in process of applying for permanent residency. The eligible study population comprised all children aged 0-5 years born between April 1, 2002 and March 31, 2012 in Ontario, who had a valid Ontario Health Insurance Plan number, did not leave the province prior to their 5th birthday, and did not experience death from a cause other than maltreatment. There were 1313595 births in Ontario in the study period. Of these children, we excluded 66504 as a result of loss of provincial health insurance from out-migration. Those with missingness on covariates of interest $(n=6217)$ deemed to be random in nature were also excluded. The final analytic sample included 1240874 children (95\% of the eligible population).

\section{Data sources}

Data were drawn from linked population-based administrative databases housed at Institute for Clinical Evaluative Sciences in Toronto, Canada. These datasets were linked using unique encoded identifiers. The Registered Persons Database contains information on birth date, sex and postal code. Canadian Census data (2001 and 2006) provide neighbourhood information at the level of a dissemination area, such as residential income quintile. Eligible children were identified via hospitalisation-related births in the Canadian Institute for Health Information Discharge Abstract Database, capturing 98\% of all births in Ontario. The National Ambulatory Care Reporting System and Canadian Institute for Health Information Discharge Abstract Database were then used, in conjunction with the International Classification of Diseases 10th Revision-Canada diagnostic codes, to ascertain emergency department visits and inpatient hospitalisations, respectively. Data from Ontario's Vital Statistics database provides details on out-of-hospital deaths. The Ontario portion of the federally maintained Immigration, Refugees, and Citizenship Canada (IRCC) Permanent Resident Database was used to provide information about a mother's birthplace and date of arrival to Canada. This database includes all immigrants who obtained permanent residence from January 1, 1985 to December 31, 2012. The overall linkage rate for the IRCC Permanent Resident Database to the Registered Persons Database is $86 \% .^{23} 24$

\section{Exposure assessment}

\section{Maternal birthplace}

Maternal birthplace is classified during the immigration application process from notarised copies of original documents and entered in the IRCC Permanent Resident Database after landing. Mothers who obtained permanent residency, including those who applied with refugee status, were categorised as immigrants. Mothers who did not have an immigration record were considered Canadian-born.

\section{Neighbourhood-level income quintiles}

Neighbourhood-level income quintiles were based on average household income adjusted for community size for the 2001 and 2006 Census dissemination area, which represents the smallest geographic census area for which data are disseminated, with a typical population of 400-700 individuals. Children were assigned to a dissemination area based on their mothers' postal code at the time of birth.
Birth order of child

Birth order as a dimension of family composition was defined as the sequence of consecutive live births from the same mother (categorised as 1 (referent), 2, 3 and 4+). Birth order was assessed based on the number of previous live births a mother had at the time of delivery of index child.

\section{Outcome assessment}

Health system-identified CM-related injuries were counted from non-fatal and fatal injuries identified in an emergency department visit, hospital admission or death-occurring from birth up to 5 th birthday. We used the International Classification of Diseases 10th Revision-Canada diagnostic codes for maltreatment, assault and injury characteristics that are consistent with $\mathrm{CM}$ and have been used in prior research using administrative health data. ${ }^{125-27}$ Outcomes were captured by diagnostic codes at the time of an emergency department visit or hospital admission and by the cause of death code among out-of-hospital deaths (online appendix 1).

The outcome has previously been operationalised using four subcategories in descending order of specificity. ${ }^{126}$ In our analysis, subcategories were combined to preserve statistical power, due to the relatively low event occurrence. These include (1) maltreatment syndrome (physical abuse, sexual abuse, psychological abuse or neglect as the cause of injury), (2) assault (violence by caregivers (physical) others, which may be due to inadequate supervision (neglect), (3) undetermined cause (explicit uncertainty about the cause of injury, which may reflect physical abuse or neglect) and (4) adverse social circumstances (physician concern about parenting, home environment or broader welfare concerns associated with the injury). ${ }^{26}{ }^{28}$ In sensitivity analyses, we excluded cases identified in emergency departments only. Further details are found in online appendix 1.

\section{Covariates}

A number of maternal and child characteristics identified a priori were treated as potential confounders. These included maternal age at delivery of child ( $\leq 19,20-34$ and $\geq 35$ years of age), childhood complex chronic conditions (yes/no), neighbourhood income quintile $(1=$ lowest to $5=$ highest $)$ and urban/rural residence (urban $\leq 40$ on Rurality Index of Ontario; rural $\geq 40$ ). Income quintile and urban/rural residence were ascertained from Canadian census data using the closest census year to the child's birth. Among immigrant mothers, time since immigration to Canada at delivery of index child $(\leq 5,6-9,10-14$ and $15+$ years) was also adjusted for, as well as refugee status, knowledge of Canadian official languages (French or English), marital status, region of birth and educational attainment at arrival. Information on child or mother's race/ethnicity was not available.

\section{Statistical analyses}

Descriptive analyses were conducted to compare the distribution of maternal and child characteristics separately by immigrant status. Stratified modified Poisson regression models were then separately fit to estimate crude and adjusted rate ratios (ARR) and corresponding 95\% CIs for maltreatment among children of immigrants compared to those of Canadian-born mothers. Models accounted for the possibility of more than one child per mother by using general estimating equations (GEE) to produce robust SEs. For assessment of linear trends across neighbourhood income quintiles and birth order within strata of immigrant and non-immigrant, these variables were re-entered in models as 
continuous. Further, a secondary analysis was conducted to assess whether patterns of CM observed were consistent across subgroups of immigrants based on region of origin, with interaction terms between maternal region of birth and neighbourhood income and birth order included in all models.

Models with the subsample of immigrants-only were additionally adjusted for characteristics only available for immigrants, such as time since immigration, refugee status, knowledge of Canadian official languages, marital status and educational attainment at arrival.

We conducted two sensitivity analyses. First, to ascertain whether observed associations were affected by data source, we repeated all analyses using a more specific outcome variable. This outcome was defined as CM documented during hospitalisations and deaths only, deemed more reliable in assessing that CM had indeed occurred. Second, since marital status and educational attainment may have changed for younger immigrant women and girls from arrival to delivery, sensitivity analyses in a subsample of immigrant mothers $\geq 25$ years at the time of arrival were conducted to improve the efficiency of adjustment and remove potential influences.

All analyses were performed using SAS version 9.4 (SAS Institute, Cary, North Carolina, USA). The study obtained ethics approval from the Research Ethics Board at the University of Toronto (protocol reference \#33799).

\section{RESULTS}

The cohort comprised 1240874 children, of whom 315218 (25.4\%) were born to immigrants and 925656 (74.6\%) to nonimmigrant mothers (table 1). CM rates were higher among children of non-immigrants mothers compared to immigrants, 1.6 per 100 children and 1.0 , respectively. Children of immigrant mothers were more often born into the lowest income quintile compared to non-immigrants $(33.4 \%$ vs $18.1 \%)$ and concentrated in urban areas. Among immigrant families only, the majority of mothers immigrated in the past 5 years, had knowledge of French or English, had 12 or more years of education and were married/common law (vs single or divorced/separated).

Neighbourhood income gradients in CM differed by immigration status ( $\mathrm{p}$ value for interaction $<0.001$ ). In analyses stratified by neighbourhood income (table 2), CM rates followed a downward gradient among non-immigrants as neighbourhood income increased, from $2.7 \%$ at Q1 (lowest income) to $1.1 \%$ at Q5 (highest income) (ARR Q1 vs Q5: 1.57, 95\% CI 1.49 to 1.66). Among children of immigrants, a similar, although attenuated, gradient was observed in the crude model, from 1.1\% at Q1 to $0.8 \%$ at $\mathrm{Q} 5$, which persisted, but with a lower magnitude, following adjustment (ARR Q1 vs Q5: 1.33, 95\% CI 1.15 to 1.54). However, after restricting in sensitivity analyses to children whose mothers were 25 years or more at arrival to Canada, the neighbourhood gradient disappeared. Exclusion of cases identified in emergency departments also made undetectable the income gradient found in the main analyses (online supple mental table 1). Compared to non-immigrants, immigrants had lower rates of CM in all quintiles, but the disparity was greatest in more deprived neighbourhoods (ARR 0.56, 95\% CI 0.52 to 0.60 at Q1 to ARR $0.81,95 \%$ CI 0.70 to 0.93 at Q5). In a secondary analysis, an interaction term between maternal region of origin and neighbourhood income was significant ( $\mathrm{p}$ value for interaction $<0.05$ ) in all three models (not shown). Region-specific results (online supplemental table 3 ) showed some evidence of $\mathrm{CM}$ rates following a downward gradient as neighbourhood income increased among children of immigrant mothers from
Eastern Europe, Western Europe/USA/Australia/New Zealand and Latin American/Caribbean regions. In contrast, non-linear gradients were observed among children of mothers from South Asia and East Asia/Pacific regions, while small sample sizes precluded meaningful interpretation of results for North Africa/ Middle East and sub-Saharan Africa regions.

In analyses stratified by birth order (table 3), crude and adjusted estimates showed a reverse pattern in the association between birth order and CM according to immigration status ( $\mathrm{p}$ value for interaction $<0.001)$. For children of non-immigrant mothers, CM for a fourth or higher-order child was $2.4 \%$ compared to $1.8 \%$ for a first child (ARR of $4+$ vs 1 st child: $1.75,95 \%$ CI 1.63 to 1.89 ). In contrast, among immigrants, incidence of maltreatment for a fourth or higher-order child was $0.6 \%$ compared to $1.1 \%$ for a first child (ARR 4+ vs 1st child: $0.57(95 \%$ CI 0.44 to 0.74$)$ ). The disparity in CM between immigrants and non-immigrants increased alongside birth order, from ARR: 0.74 (95\% CI 0.70 to 0.78 ) at first child to ARR: 0.28 (95\% CI 0.22 to 0.37 ) at fourth or higher-order child. Restriction to maternal age $\geq 25$ years did not affect these results. Exclusion of cases identified in emergency departments did not change results (online supplemental table 2). In a secondary analysis, an interaction term between maternal region of origin and birth order was not significant at $\mathrm{p}$ value of $<0.2$ and therefore results are not shown.

\section{DISCUSSION}

We found a robust neighbourhood socioeconomic gradient in the rate of health system-identified maltreatment among children of non-immigrant mothers and a less consistent one among immigrants. We also found that within-income quintile differences in CM by immigrant status were highest in the most deprived neighbourhood income quintile and less pronounced in mediumincome to high-income quintiles. Modification of the association between childbirth order and CM according to immigrant status was also observed, but showed inverse patterns, where higher birth order was negatively associated with maltreatment among children of immigrants, and positively associated among children of non-immigrants.

Our finding of a weak gradient between neighbourhood income and CM among immigrants supports previous research, which, though limited by differing study methods and variables, show little 1819 or no association between socioeconomic position and CM in this population. ${ }^{7} 17$ The apparent weak association in earlier studies, however, is likely to involve prevailing confounding by refugee status, due to refugees' underlying accumulation of adverse life circumstances. Thus, a unique aspect of the current analysis was our adjustment for refugee status, and while our data do not confirm a strong gradient, findings extend the literature in two key ways.

First, our results show that the neighbourhood income-CM gradient disappears among children of immigrant mothers who arrived to Canada at 25 or more years, suggesting that the steepening gradient among immigrants in main results is explained by children of younger mothers ( $<25$ years) who arrived as children/adolescents and lived on average 10 years in Canada prior to having children. This may reflect evidence of the 'segmented assimilation hypothesis', which specifies how immigrants are gradually assimilated into the social stratification system of the receiving society, ${ }^{29}$ resulting in neighbourhood-level deprivation becoming more influential in incidence of CM among immigrants over time. Another explanation may be that since recent immigrants have a higher tendency to settle in rental dwellings in low-income neighbourhoods irrespective of higher educational 
Table 1 Characteristics of 5-year-old Ontario-born children by immigrant status, Canada, 2002-2012

\begin{tabular}{|c|c|c|c|c|c|}
\hline & \multicolumn{2}{|c|}{ Non-immigrants } & \multicolumn{2}{|c|}{ Immigrants } & \multirow[b]{2}{*}{ Standardised differences } \\
\hline & $\mathrm{N}$ & $\%$ & $\mathrm{~N}$ & $\%$ & \\
\hline Total & 925656 & & 315218 & & \\
\hline \multicolumn{6}{|l|}{ Child characteristics } \\
\hline Child maltreatment (emergency deparment + hospitalisation) & 14952 & 1.6 & 3015 & 1.0 & 0.06 \\
\hline Child maltreatment (hospitalisation only) & 4266 & 0.5 & 813 & 0.3 & 0.03 \\
\hline Male sex & 474585 & 51.3 & 161927 & 51.4 & 0.0 \\
\hline Complex chronic conditions & 48252 & 5.2 & 17332 & 5.5 & -0.01 \\
\hline \multicolumn{6}{|l|}{ Birth order } \\
\hline $1 \mathrm{st}$ & 455920 & 49.3 & 181857 & 57.7 & -0.17 \\
\hline 2nd & 328709 & 35.5 & 96624 & 30.7 & 0.1 \\
\hline $3 r d$ & 105169 & 11.4 & 27266 & 8.6 & 0.09 \\
\hline 4 th+ & 35858 & 3.9 & 9471 & 3.0 & 0.05 \\
\hline \multicolumn{6}{|l|}{ Neighbourhood income quintile } \\
\hline 1: Lowest & 167176 & 18.1 & 105437 & 33.4 & -0.36 \\
\hline 2 & 174969 & 18.9 & 72986 & 23.2 & -0.1 \\
\hline 3 & 193539 & 20.9 & 60188 & 19.1 & 0.05 \\
\hline 4 & 210733 & 22.8 & 48546 & 15.4 & 0.19 \\
\hline 5: Highest & 179239 & 19.4 & 28061 & 8.9 & 0.3 \\
\hline Rural residence & 121548 & 13.1 & 3055 & 1.0 & 0.49 \\
\hline \multicolumn{6}{|l|}{ Maternal characteristics } \\
\hline \multicolumn{6}{|l|}{ Maternal age, years } \\
\hline$\leq 19$ & 40169 & 4.3 & 4439 & 1.4 & 0.18 \\
\hline $20-24$ & 127955 & 13.8 & 36808 & 11.7 & 0.06 \\
\hline $25-29$ & 255437 & 27.6 & 95251 & 30.2 & -0.06 \\
\hline $30-34$ & 316766 & 34.2 & 105829 & 33.6 & 0.01 \\
\hline $35-39$ & 155730 & 16.8 & 59237 & 18.8 & -0.05 \\
\hline $40+$ & 29599 & 3.2 & 13654 & 4.3 & -0.06 \\
\hline \multicolumn{6}{|l|}{ Maternal birthplace } \\
\hline Canadian-born & 925656 & 100 & & & \\
\hline South Asia & & & 103083 & 32.7 & \\
\hline East Asia/Pacific & & & 71858 & 22.8 & \\
\hline Latin America/Caribbean & & & 43391 & 13.8 & \\
\hline North Africa/Middle East & & & 25682 & 8.1 & \\
\hline Western Europe, USA, Australia, New Zealand & & & 24687 & 7.8 & \\
\hline Eastern Europe & & & 23802 & 7.6 & \\
\hline Sub-Saharan Africa & & & 22715 & 7.2 & \\
\hline \multicolumn{6}{|l|}{ Time since maternal immigration, years } \\
\hline$<5$ & & & 166938 & 53.0 & \\
\hline $5-9$ & & & 73841 & 23.4 & \\
\hline $10-14$ & & & 43619 & 13.8 & \\
\hline $15+$ & & & 30820 & 9.8 & \\
\hline Received refugee status & & & 39959 & 12.7 & \\
\hline Knowledge of Canadian official languages & & & 192856 & 61.2 & \\
\hline \multicolumn{6}{|l|}{ Marital status at arrival } \\
\hline Married/common law & & & 185224 & 58.8 & \\
\hline Single & & & 127136 & 40.3 & \\
\hline Divorced/separated/widowed & & & 2858 & 0.9 & \\
\hline \multicolumn{6}{|l|}{ Educational attainment at arrival } \\
\hline$<12$ years & & & 124411 & 39.5 & \\
\hline $12+$ years & & & 190807 & 60.5 & \\
\hline Landed in Canada at age 25+ years & & & 153374 & 48.7 & \\
\hline
\end{tabular}


Table 2 Neighbourhood income gradient in early childhood maltreatment among 5-year-old Ontario-born children, stratified by immigrant status, Canada, 2002-2012

\begin{tabular}{|c|c|c|c|c|c|c|c|c|c|c|c|c|c|c|c|c|c|c|}
\hline & \multicolumn{6}{|c|}{ Non-immigrants } & \multicolumn{7}{|c|}{ Immigrants } & \multicolumn{3}{|c|}{$\begin{array}{l}\text { Immigrants } \\
\geq 25 \text { years }\end{array}$} & \multicolumn{2}{|c|}{$\begin{array}{l}\text { Immigrants } \\
\text { vs non- } \\
\text { immigrants }\end{array}$} \\
\hline & Cases & $\begin{array}{l}\text { Rate } \\
\text { per } 100 \\
\text { children }\end{array}$ & $\mathbf{R R}$ & $95 \% \mathrm{Cl}$ & ARR* & $95 \% \mathrm{Cl}$ & Cases & $\begin{array}{l}\text { Rate } \\
\text { per } 100 \\
\text { children }\end{array}$ & $\mathbf{R R}$ & $95 \% \mathrm{Cl}$ & ARR* & $95 \% \mathrm{Cl}$ & ARRt & $95 \% \mathrm{Cl}$ & ARR $†$ & $\begin{array}{l}95 \% \\
\mathrm{Cl}\end{array}$ & ARR* & $\begin{array}{l}95 \% \\
\mathrm{Cl}\end{array}$ \\
\hline \multicolumn{19}{|c|}{ Income quintile } \\
\hline 1: Lowest & 4466 & 2.7 & 2.30 & $\begin{array}{l}2.18 \\
2.43\end{array}$ & 1.57 & $\begin{array}{l}1.49 \\
1.66\end{array}$ & 1168 & 1.1 & 1.38 & $\begin{array}{l}1.20 \\
1.58\end{array}$ & 1.38 & $\begin{array}{l}1.20 \\
1.58\end{array}$ & 1.33 & $\begin{array}{l}1.15 \\
1.54\end{array}$ & 1.08 & $\begin{array}{l}0.89 \\
1.33\end{array}$ & 0.56 & $\begin{array}{l}0.52 \\
0.60\end{array}$ \\
\hline 2 & 3162 & 1.8 & 1.28 & $\begin{array}{l}1.21 \\
1.35\end{array}$ & 1.33 & $\begin{array}{l}1.63 \\
1.89\end{array}$ & 708 & 1.0 & 1.22 & $\begin{array}{l}1.06 \\
1.41\end{array}$ & 1.22 & $\begin{array}{l}1.05 \\
1.41\end{array}$ & 1.20 & $1.03,1.40$ & 1.02 & $\begin{array}{l}0.83 \\
1.26\end{array}$ & 0.67 & $\begin{array}{l}0.62 \\
0.73\end{array}$ \\
\hline 3 & 2741 & 1.4 & 1.12 & $\begin{array}{l}1.05 \\
1.18\end{array}$ & 1.14 & $\begin{array}{l}1.12 \\
1.25\end{array}$ & 536 & 0.9 & 1.11 & $\begin{array}{l}0.96 \\
1.29\end{array}$ & 1.11 & $\begin{array}{l}0.95 \\
1.30\end{array}$ & 1.12 & $\begin{array}{l}0.95 \\
1.31\end{array}$ & 0.95 & $\begin{array}{l}0.76 \\
1.18\end{array}$ & 0.76 & $\begin{array}{l}0.69 \\
0.83\end{array}$ \\
\hline 4 & 2568 & 1.2 & 1.04 & $\begin{array}{l}0.98 \\
1.11\end{array}$ & 1.06 & $\begin{array}{l}0.96 \\
1.03\end{array}$ & 379 & 0.8 & 0.97 & $\begin{array}{l}0.83 \\
1.14\end{array}$ & 0.98 & $\begin{array}{l}0.83 \\
1.15\end{array}$ & 0.98 & $\begin{array}{l}0.84 \\
1.15\end{array}$ & 0.94 & $\begin{array}{l}0.75 \\
1.17\end{array}$ & 0.73 & $\begin{array}{l}0.66 \\
0.82\end{array}$ \\
\hline 5: Highest & 2015 & 1.1 & 1.00 & Ref. & 1.00 & Ref. & 224 & 0.8 & 1.00 & Ref. & 1.00 & Ref. & 1.00 & Ref. & 1.00 & Ref. & 0.81 & $\begin{array}{l}0.70 \\
0.93\end{array}$ \\
\hline RR for trend & & & 1.25 & $\begin{array}{l}1.24 \\
1.27\end{array}$ & 1.12 & $\begin{array}{l}1.11 \\
1.14\end{array}$ & & & 1.10 & $\begin{array}{l}1.06 \\
1.12\end{array}$ & 1.09 & $\begin{array}{l}1.05 \\
1.12\end{array}$ & 1.09 & $\begin{array}{l}1.05 \\
1.12\end{array}$ & 1.03 & $\begin{array}{l}0.99 \\
1.08\end{array}$ & & \\
\hline $\begin{array}{l}\text { P value for } \\
\text { trend }\end{array}$ & & & & $<0.0001$ & & $<0.0001$ & & & & $<0.0001$ & & $<0.0001$ & & $<0.0001$ & & 0.10 & & \\
\hline
\end{tabular}

*Adjusted for maternal age, child sex, rural residence, complex chronic conditions and birth order.

†Adjusted for maternal age, child sex, rural residence, complex chronic conditions, birth order, maternal region of birth, duration of residence in Canada, refugee status, knowledge of Canadian official languages, marital status at arrival and educational attainment at arrival.

$A R R$, adjusted rate ratio; $C M$, child maltreatment; $R R$, rate ratio.

Table 3 Birth order gradient in early childhood maltreatment among 5-year-old Ontario-born children, stratified by immigrant status, Canada, 2002-2012

\begin{tabular}{|c|c|c|c|c|c|c|c|c|c|c|c|c|c|c|c|c|c|c|}
\hline & \multicolumn{6}{|c|}{ Non-immigrants } & \multicolumn{7}{|c|}{ Immigrants } & \multicolumn{3}{|c|}{$\begin{array}{l}\text { Immigrants } \\
\geq 25 \text { years }\end{array}$} & \multicolumn{2}{|c|}{$\begin{array}{l}\text { Immigrants } \\
\text { vs non- } \\
\text { immigrants }\end{array}$} \\
\hline & Cases & $\begin{array}{l}\text { Rate per } \\
100 \\
\text { children }\end{array}$ & $\mathbf{R R}$ & $95 \% \mathrm{Cl}$ & ARR* & $95 \% \mathrm{Cl}$ & Cases & $\begin{array}{l}\text { Rate per } \\
100 \\
\text { children }\end{array}$ & RR & $95 \% \mathrm{Cl}$ & ARR* & $95 \% \mathrm{Cl}$ & ARRt & $95 \% \mathrm{C}$ & I ARRT & $95 \% \mathrm{Cl}$ & $A R R^{*}$ & $\begin{array}{l}95 \% \\
\mathrm{Cl}\end{array}$ \\
\hline \multicolumn{19}{|c|}{ Birth order } \\
\hline $1 \mathrm{st}$ & 8055 & 1.8 & 1.00 & Ref. & 1.00 & Ref. & 1991 & 1.1 & 1.00 & Ref. & 1.00 & Ref. & 1.00 & Ref. & 1.00 & Ref. & 0.74 & $\begin{array}{l}0.70 \\
0.78\end{array}$ \\
\hline 2nd & 4426 & 1.4 & 0.76 & $\begin{array}{l}0.74 \\
0.79\end{array}$ & 1.00 & $\begin{array}{l}0.96 \\
1.03\end{array}$ & 766 & 0.8 & 0.72 & $\begin{array}{l}0.67 \\
0.78\end{array}$ & 0.77 & $\begin{array}{l}0.71 \\
0.84\end{array}$ & 0.75 & $\begin{array}{l}0.69 \\
0.82\end{array}$ & 0.72 & $\begin{array}{l}0.66 \\
0.86\end{array}$ & 0.64 & $\begin{array}{l}0.59 \\
0.69\end{array}$ \\
\hline $3 r d$ & 1629 & 1.6 & 0.85 & $\begin{array}{l}0.81 \\
0.90\end{array}$ & 1.18 & $\begin{array}{l}1.12 \\
1.25\end{array}$ & 198 & 0.7 & 0.66 & $\begin{array}{l}0.57 \\
0.76\end{array}$ & 0.70 & $\begin{array}{l}0.61 \\
0.82\end{array}$ & 0.66 & $\begin{array}{l}0.56 \\
0.76\end{array}$ & 0.57 & $\begin{array}{l}0.43 \\
0.76\end{array}$ & 0.51 & $\begin{array}{l}0.44 \\
0.60\end{array}$ \\
\hline $4+$ & 842 & 2.4 & 1.25 & $\begin{array}{l}1.16 \\
1.35\end{array}$ & 1.75 & $\begin{array}{l}1.63 \\
1.89\end{array}$ & 60 & 0.6 & 0.57 & $\begin{array}{l}0.44 \\
0.74\end{array}$ & 0.59 & $\begin{array}{l}0.45 \\
0.76\end{array}$ & 0.52 & $\begin{array}{l}0.39 \\
0.67\end{array}$ & 0.51 & $\begin{array}{l}0.32 \\
0.81\end{array}$ & 0.28 & $\begin{array}{l}0.22 \\
0.37\end{array}$ \\
\hline $\begin{array}{l}\text { RR for } \\
\text { trend }\end{array}$ & & & 0.95 & $\begin{array}{l}0.93 \\
0.98\end{array}$ & 1.13 & $\begin{array}{l}1.11 \\
1.15\end{array}$ & & & 0.79 & $\begin{array}{l}0.75 \\
0.83\end{array}$ & 0.82 & $\begin{array}{l}0.78 \\
0.86\end{array}$ & 0.79 & $\begin{array}{l}0.74 \\
0.84\end{array}$ & 0.76 & $\begin{array}{l}0.69 \\
0.84\end{array}$ & & \\
\hline $\begin{array}{l}\text { P value } \\
\text { for trend }\end{array}$ & & & & $<0.0001$ & & $<0.0001$ & & & & $<0.0001$ & & $<0.0001$ & & $<0.000$ & & $<0.0001$ & & \\
\hline
\end{tabular}

${ }^{*}$ Adjusted for maternal age, child sex, rural residence, complex chronic conditions and neighbourhood income.

†Adjusted for maternal age, child sex, rural residence, complex chronic conditions, neighbourhood income, maternal region of birth, duration of residence in Canada, refugee status, knowledge of Canadian official languages, marital status at arrival and educational attainment at arrival.

$A R R$, adjusted rate ratio; $C M$, child maltreatment; $R R$, rate ratio.

credentials and two-parent family status, ${ }^{30}$ they are more likely to be misclassified with respect to true socioeconomic status, thus accounting for the absent gradient among immigrant mothers who were older at arrival. Second, our results indicate that being a child of an immigrant is most protective in lowestincome neighbourhoods and more modest in higher-income neighbourhoods. This finding could reflect the beneficial effect of residing within an immigrant enclave or network, where shared immigrant status may increase social support and community cohesion to diminish the effects of poverty and lower parenting stress. ${ }^{31} 32$ Another potential explanation for this attenuation may be that the effect of neighbourhood poverty on $\mathrm{CM}$ in immigrant families operates through different pathways than those of receiving-society families in similarly deprived neighbourhoods. In line with prior literature, one plausible interpretation is that immigrant families in low-income 
neighbourhoods are more likely transiently, rather than persistently, poor as their non-immigrant counterparts. ${ }^{31}$ For immigrants, this distinct context of poverty, often viewed as an inevitable part of the resettlement process, ${ }^{16}$ is more likely to have fewer health-deteriorating consequences on children compared with those living in more entrenched poverty. ${ }^{32}$ Taken together, these findings support and extend the CM literature on the 'healthy immigrant effect', ${ }^{33}$ pointing to a protective effect of immigrant status in buffering against influences of neighbourhood deprivation on health system-identified CM, which was strongest for children of recent immigrants in lowest-income neighbourhoods and appeared to attenuate with the resettlement process.

Our finding of an inverse relationship between birth order and CM among children of immigrants, compared to nonimmigrants, presents additional evidence of an immigrant advantage in preventing $\mathrm{CM},{ }^{13} 22$ though mechanisms underlying this pattern remain unclear. As findings by Milan et $a^{34}$ show that $8 \%$ of Canada's older immigrant population coresided in a home with grandchildren, compared to less than $3 \%$ of their nonimmigrant counterparts, coresiding grandparents may be one potential factor offsetting the influence between strained resources and risk of $\mathrm{CM}$ in larger immigrant families. ${ }^{35}$ Another potential explanation may be culturally informed practices of sibling caretaking among immigrant families, where older children supervise and care for younger children ${ }^{7}$; however, further investigation is warranted.

There are several strengths to our study. First, our data comprise a large population-based sample, allowing for almost complete coverage of the target population and adjustment for a wide range of covariates, including refugee status among immigrant mothers. Second, the longitudinal data allowed us to follow children for 5 years and obtain information on all health systemidentified CM. Third, we used sensitivity analyses to assess unmeasured confounding by resettlement-related factors and outcome misclassification, which reported robust birth order and weak socioeconomic gradients in CM among immigrants.

Our findings also must be interpreted within study limitations. The study's primary limitation is classification of our CM outcome, which cannot be captured with a high degree of certainty due to the limitations of health system-identified CM and lack of available CM variables not captured by health system identification, including reports from CPS. Second, we could not adjust for potential confounders at the individual level among nonimmigrant mothers, such as education and marital status, to more accurately draw comparisons with immigrants. Also, while immigration data are reliable, individual-level confounders were measured at arrival to Canada and not at birth of index child, which may introduce time-varying confounding, as well as not account for other factors influencing the resettlement process. Third, since neighbourhood income is an aggregate measure, it may not accurately reflect household income, particularly in neighbourhoods with more inequality in the distribution of individual/household income. Additionally, since neighbourhood income was assessed in the 2001 and 2006 Census only and determined based on dissemination area of mothers' postal code at time of index child's birth, there is potential for misclassification of a child's neighbourhood income quintile. Fourth, we do not know the immigration status of fathers and thus cannot account for the potential influences of paternal immigration status on CM risk. Fifth, due to unavailable data, we could not adjust for or stratify results by children's race/ethnicity, which ample evidence ${ }^{4-6}$ suggests is a strong predictor of CM reporting and contact with CPS. Though our secondary analysis examined patterns among immigrants by region of origin, we acknowledge that this is an inadequate proxy for race/ethnicity, and further, our analysis was underpowered for meaningful interpretation. Future research should consider racial/ethnic disparities in health system-identified CM in Canada, including attention to roles of anti-Black racism and anti-immigrant sentiment in influencing clinical decision-making around CM reporting and a family's exposure to CPS. Finally, our study sample includes children of documented (status) immigrant mothers only and does not address the experiences of children of undocumented (nonstatus) mothers. As no known studies have examined non-status immigrant families and CM in Canada, future work is needed to better understand the experiences of these families, who are more likely to face disparate access to support services, and for whom the consequences of CM and involvement in CPS may be costlier, resulting in loss of eligibility for immigrant status, as well as deportation. $^{7}$

In conclusion, differences in patterns of risk and protective factors for CM demonstrate the role of neighbourhood-level and family-level associations among children of immigrants and non-immigrants. The wide socioeconomic disparity in maltreatment among children of non-immigrant mothers and less pronounced disparity among immigrants indicate concerning income-based health disparities that add to the disproportionate burden of poor health facing children in deprived neighbourhoods. Findings suggest that although immigrants are disproportionately concentrated in poorer neighbourhoods, the mechanism of neighbourhood income is less consistently associated with CM in this population. Future research should consider alternative mechanisms that may account for why children in immigrant families appear to be protected from some of the jeopardising impacts of neighbourhood poverty, as well as examine the extent to which patterns may vary across race/ethnicity and nativity composition of neighbourhoods. ${ }^{36}$ The robust inverse pattern between birth order and CM rates according to immigrant status requires further explanation in future studies.

\section{What is already known on this subject}

- Literature in the general population shows strong gradients in child maltreatment by socioeconomic status and family composition. If, and how, these patterns extend to immigrant families, who are more likely to live on lower incomes and have larger families, however, are unknown.

\section{What this study adds}

- This is the first population-based cohort study to examine whether there are socioeconomic and birth order gradients in health system-identified child maltreatment according to immigrant status.

- Children of immigrants exhibited lower maltreatment rates than non-immigrants across neighbourhood income levels. The protective effect of immigrant status was strongest for children of recent immigrants residing in the most deprived neighbourhoods and appeared to attenuate with the resettlement process.

- Inverse birth order gradients in maltreatment between children of immigrants and non-immigrants present robust evidence of an immigrant advantage in buffering maltreatment risk.

- Findings extend understanding of dimensions of the 'healthy immigrant effect' in population-based maltreatment data. 


\section{Author affiliations}

${ }^{1}$ Department of Community Health Sciences, Max Rady College of Medicinea, University of Manitoba, Winnipeg, Canada

${ }^{2}$ Department of Epidemiology, Dalla Lana School of Public Health, University of Toronto, Toronto, Canada

${ }^{3}$ Li Ka Shing Knowledge Institute, St.Michael's Hospital, Toronto, Canada ${ }^{4}$ Division of Paediatric Medicine, Hospital for Sick Children, Toronto, Canada ${ }^{5}$ Department of Pediatrics, Faculty of Medicine, University of Toronto, Toronto, Canada

${ }^{6}$ Institute for Clinical Evaluative Sciences, Toronto, Canada

${ }^{7}$ Institute of Health Policy, Management and Evaluation, Faculty of Medicine, University of Toronto, Toronto, Canada

Correction notice This article has been corrected since it first published online. Affiliation 2 has been added to the author Marcelo Urquia.

Contributors KSK, AP and MLU conceived the study and developed the analytic strategy. AG and POC contributed to study design. AP, MLU and KSK analysed the data. KSK led the writing of the manuscript. All authors made significant contributions to the interpretation of the data, drafting of the article and approved the final version of the manuscript.

Funding KSK is supported by MLU's CIHR Foundation Grant (CIHR FDN-154280). MLU is supported by a Canadian Research Chair in Applied Population Health. This study was supported by ICES, which is funded by an annual grant from the Ontario Ministry of Health and Long-Term Care (MOHLTC). The opinions, results and conclusions reported in this article are those of the authors and are independent from the funding sources. No endorsement by ICES or the Ontario MOHLTC is intended or should be inferred. Parts of this material are based on data and information compiled and provided by the Canadian Institute for Health Information ( $\mathrm{ClHI}$ ). However, the analyses, conclusions, opinions and statements expressed herein are those of the authors and not necessarily those of $\mathrm{CIHI}$.

Competing interests None declared.

Patient consent for publication Not required.

Provenance and peer review Not commissioned; externally peer reviewed.

Data availability statement Data used for the current study are held securely at ICES in Ontario, Canada. Data sharing agreements prohibit ICES from making the dataset publicly available.

Supplemental material This content has been supplied by the author(s). It has not been vetted by BMJ Publishing Group Limited (BMJ) and may not have been peerreviewed. Any opinions or recommendations discussed are solely those of the author(s) and are not endorsed by BMJ. BMJ disclaims all liability and responsibility arising from any reliance placed on the content. Where the content includes any translated material, BMJ does not warrant the accuracy and reliability of the translations (including but not limited to local regulations, clinical guidelines, terminology, drug names and drug dosages), and is not responsible for any error and/ or omissions arising from translation and adaptation or otherwise.

Open access This is an open access article distributed in accordance with the Creative Commons Attribution Non Commercial (CC BY-NC 4.0) license, which permits others to distribute, remix, adapt, build upon this work non-commercially, and license their derivative works on different terms, provided the original work is properly cited, appropriate credit is given, any changes made indicated, and the use is noncommercial. See: http://creativecommons.org/licenses/by-nc/4.0/.

ORCID iD

Kathleen S Kenny http://orcid.org/0000-0001-9531-5213

\section{REFERENCES}

1 Gilbert R, Fluke J, O'Donnell $M$, et al. Child maltreatment: variation in trends and policies in six developed countries. Lancet 2012;379:758-72.

2 Berger LM, Waldfogel J. Economic determinants and consequences of child maltreatment. OECD Soc Employ Migr Work Pap 2011:1-31.

3 Pelton $\mathrm{LH}$. The continuing role of material factors in child maltreatment and placement. Child Abus Negl 2015;41:30-9.

4 Wildeman C, Emanuel N. Cumulative risks of foster care placement by age 18 for US children, 2000-2011. PLoS One 2014;9:e92785.

5 Trocmé N, Knoke D, Blackstock C. Pathways to the overrepresentation of aboriginal children in Canada's child welfare system. Soc Serv Rev 2004:78:577-600.
6 Roberts D. Shattered bonds: the color of child welfare. Civitas Books, 2009.

7 Dettlaff AJ, Earner I. Children of immigrants in the child welfare system: characteristics, risk, and maltreatment. Fam Soc 2012;93:295-303.

8 Euser EM, Van IMH, Prinzie P, et al. Elevated child maltreatment rates in immigrant families and the role of socioeconomic differences. Child Maltreat 2011;16:63-73.

9 Putnam-Hornstein E, Needell B, Rhodes AE. Understanding risk and protective factors for child maltreatment: the value of integrated, population-based data. Child Abuse Negl 2013;37:116-19.

10 Berger J, Dettlaff AJ, Finno-velasquez M, et al. Children and youth services review nativity and immigration status among Latino families involved in the child welfare system: characteristics, risk, and maltreatment. Child Youth Serv Rev 2014;44:189-200.

11 Dettlaff AJ, Johnson MA. Children and youth services review child maltreatment dynamics among immigrant and U . S . born Latino children : findings from the National Survey of Child and Adolescent Well-being (NSCAW). Child Youth Serv Rev 2011:33:936-44.

12 Millett LS. The healthy immigrant paradox and child maltreatment : a systematic review. J Immigr Minor Heal 2016;18:1199-215.

13 Berger LM. Income, family structure, and child maltreatment risk. Child Youth Serv Rev 2004;26:725-48.

14 Conger RD, Ge X, Elder Jr GH, et al. Economic stress, coercive family process, and developmental problems of adolescents. Child Dev 1994;65:541-61.

15 Conger RD, Wallace LE, Sun Y, et al. Economic pressure in African American families: a replication and extension of the family stress model. Dev Psychol 2002;38:179.

16 Beiser M, Hou F, Hyman I, et al. Poverty, family process, and the mental health of immigrant children in Canada. Am J Public Health 2002;92:220-7.

17 Vinnerljung B, Franzén E, Gustafsson B, et al. Out-of-home care among immigrant children in Sweden: a national cohort study. Int I Soc Welf 2008;17:301-11.

18 Alink LR, Euser S, van lizendoorn MHB-KM. Is elevated risk of child maltreatment in immigrant families associated with socioeconomic status? Evidence from three sources. Int J Psychol 2013;48:117-27.

19 Schick M, Schönbucher V, Landolt MA, et al. Child maltreatment and migration: a population-based study among immigrant and native adolescents in Switzerland. Child Maltreat 2016:21:3-15

20 Stith SM, Liu T, Davies LC, et al. Risk factors in child maltreatment: a meta-analytic review of the literature. Aggress Violent Behav 2009:14:13-29.

21 Statistics Canada. Immigration and ethnocultural diversity in Canada. 2011.

22 Mason SM, Schnitzer PG, Danilack VA, et al. Risk factors for maltreatment-related infant hospitalizations in New York City, 1995-2004. Ann Epidemiol 2018;28:590-6.

23 Urquia ML, Ray JG, Wanigaratne S, et al. Variations in male-female infant ratios among births to Canadian-and Indian-born mothers, 1990-2011: a population-based register study. C Open 2016;4:E116.

24 Ray JG, Henry DA, Urquia ML. Sex ratios among Canadian liveborn infants of mothers from different countries. Can Med Assoc J 2012;cmaj-120165.

25 Scott D, Tonmyr L, Fraser J, et al. The utility and challenges of using ICD codes in child maltreatment research: a review of existing literature. Child Abuse Negl 2009:33:791-808

26 Gonzalez-izquierdo A, Ward A, Donnell MO, et al. Cross-country comparison of victimisation-related injury admission in children and adolescents in England and Western Australia. BMC Health Serv Res 2013;13:1.

27 Limbos MAP, Berkowitz CD. Documentation of child physical abuse: how far have we come? Pediatrics 1998;102:53-8.

28 Schnitzer PG, Slusher PL, Kruse RL, et al. Identification of ICD codes suggestive of child maltreatment. Child Abuse Neg/ 2011;35:3-17.

29 Zhou M. Segmented assimilation: issues, controversies, and recent research on the new second generation. Int Migr Rev 1997;31:975-1008.

30 Urquia ML, Frank JW, Glazier RH, et al. Birth outcomes by neighbourhood income and recent immigration in Toronto. Heal Reports 2007;18:21.

31 Urquia ML, O'Campo PJ, Heaman MI. Revisiting the immigrant paradox in reproductive health: the roles of duration of residence and ethnicity. Soc Sci Med 2012;74:1610-21.

32 Duncan GJ, Brooks-Gunn J. Family poverty, welfare reform, and child development. Child Dev 2000;71:188-96.

33 Putnam-Hornstein E, Needell B, King B, et al. Racial and ethnic disparities: a population-based examination of risk factors for involvement with child protective services. Child Abuse Negl 2013;37:33-46.

34 Milan A, Laflamme N, Wong I. Diversity of grandparents living with their grandchildren. Statistics Canada, 2015

35 Hernandez DJ. Demographic change and the life circumstances of immigrant families. Futur Child 2004;14:17-47.

36 Viruell-Fuentes EA, Miranda PY, Abdulrahim S. More than culture: structural racism, intersectionality theory, and immigrant health. Soc Sci Med 2012;75:2099-106. 